\title{
Protocol Deviation Subcategory
}

National Cancer Institute

\section{Source}

National Cancer Institute. Protocol Deviation Subcategory. NCI Thesaurus. Code C87996.

A subdivision of protocol deviation data. 